\title{
Wee1-Like Protein Kinase
}

National Cancer Institute

\section{Source}

National Cancer Institute. Wee1-Like Protein Kinase. NCI Thesaurus. Code C92677.

Wee1-like protein kinase (646 aa, $\sim 72 \mathrm{kDa}$ ) is encoded by the human WEE1 gene. This protein plays a role in cell cycle progression and protein phosphorylation. 